\title{
Moral Standards in the Psychological Structure of the Personality of Students of Higher Education Institutions
}

\author{
Anna Liakisheva ${ }^{1,{ }^{*}}$, Ihor Salamakha ${ }^{2}$, Liudmyla Malimon ${ }^{1}$, Nataliia Khanykina ${ }^{3}$, \\ Maryna Fedorenko ${ }^{4}$ and Yuliia Makieshyna ${ }^{5}$ \\ ${ }^{1}$ Lesya Ukrainka Volyn National University, Lutsk, Ukraine \\ ${ }^{2}$ Ukrainian National Forestry University, Lviv, Ukraine \\ ${ }^{3}$ Borys Grinchenko Kyiv University, Kyiv, Ukrain \\ ${ }^{4}$ National Pedagogical Dragomanov University, Kyiv, Ukraine \\ ${ }^{5}$ Prydniprovsk State Academy of Physical Culture and Sport, Dnipro, Ukraine
}

\begin{abstract}
In this article's scientific space, one can observe the differentiation of the definition of the terms "value", "value orientations" because it does not yet have a clear standard definition. Many researchers have dealt with this topic, researched, analyzed, observed, and made conclusions. However, there is still a rich scope for research of such phenomena of personal structure as value orientations.

Outstanding psychologists-researchers who, in their scientific, practical, and theoretical works, dealt with the topic of values and value orientations and came to the general conclusion that values are a structural component of a personality, with the help of which a person achieves a goal, sets this goal, and characterizes position in life.

The article saw the relationship between values and the basic structures of the personality, including value orientationsconsidered in values a system of orientation and personality attitudes.
\end{abstract}

Keywords: Value, orientations, the formation of orientations, Regulators.

\section{NTRODUCTION}

The modern world is now going through very difficult times. Every person, every personality is transformed and changed. A change in one person means a change in society. Each company has a unique value-oriented structure that reflects the identity of the culture. Because of the set of values that an individual assimilates in the process of socialization, society is "translated", the study of the system of personal value orientations appears to be a particularly urgent problem in a situation of serious social change, if there is some "blurring" of social value structure, there is damage many values, social structures will disappear from norms.

As profound changes occur in all spheres of world life, work is becoming even more important and of scientific value. Now it is important to understand society's needs and motives, each individual to be taken separately.

Therefore, the purpose of the article is a comprehensive analysis of values and value orientations as regulators of human behavior as a representative of society.

*Address correspondence to this author at the Lesya Ukrainka Volyn National University, Lutsk, Ukraine; Tel: +380731151635;

E-mail: maxnik8888@gmail.com
Personal values are formed based on social needs. Their implementation takes place in general social and general class conditions. In science, the concept of "value orientations" correlates with the value standards of the group, class, nation, and social system on the one hand and with the individual's motivational orientations on the other.

\section{MAIN TEXT}

At the present stage of development of scientific thought about value orientations, we can observe the fragmentation of opinions regarding the concepts of "value", "value orientations," and "value orientations of the individual." Cardinal changes in our society's political, economic, and spiritual spheres entail significant changes in the values, motives, and actions of people. The tendency towards changes over the past year is especially pronounced, so our country is going through a difficult time. There is a change in values and aspirations in the minds of citizens. In conditions of total stress and breaking of the existing foundations of behavior, there is a reassessment of each individual's values. Therefore, we say that this topic is of particular relevance in studying the theoretical and practical aspects of this psychological phenomenon. 
The concept of "value" has become the subject of extensive research in many sciences, but there is still no consensus among researchers regarding the phenomenon of values. In general, it is possible to distinguish three sacrificial subject approaches to the consideration of the concept of "value" as: a social problem (T. Butkovsky, 1997), a pedagogical problem (A. Vishnevsky, 2005), a psychological problem (I. Bulakh, 2011). Value is the property of a certain object to satisfy a certain human need, is reflected in the human imagination as the positive significance of this object.

The system of value orientations is interpreted as: a process that results in the subordination of values and the image of differentiation of objects by significance (A. Petrovsky, 2002), a variety of dispositional formations (V. Yadov, 1994), a system of attitudes regarding reality (D. Uznadze, 2004) awareness of the individual's own attitude to the surrounding reality, to herself (T. Sadova, 2010), a selective system of the orientation of the interests and needs of the individual, is aimed at a certain aspect of social values (V. Voytko, 1982), components of a conscious picture of the future (E. Golovakha, 1984), the general "acceptable" meaning of life (A. Leontiev, 1997) and others.

Generalizing in the studies of these authors is that value orientations are the most important structural component of the personality, its "core", which characterizes not only the means by which the goal is achieved but also the very goal of human activity, moreover, his life position, their main content.

R. Nemov, by value orientations he understands what a person especially values in life, to which he gives a special, positive life meaning (Babasov $\mathrm{E}$, 2001).

E. Volkov defined value orientations as a conscious regulator of a person's social behavior. He said that value orientations play a motivational role and determine the choice of activity (Andreeva G, 2004).

A. Leont'ev, considering value orientations, noted that this is the leading motive - the goal rises to the truly human, the person is not separated but merges his life with the life of people, their good. Such life motives can create an internal psychological justification of existence, which is the meaning of life."

S. Rubinstein said that value is the significance for a person of something in the world, and only when the value is recognized is it capable of performing the most important value function - the function of a guideline for behavior. Value orientation is manifested in a certain direction of consciousness and behavior, with socially significant deeds and actions (Badmaev B, 2001).

A. Zdravomislov defines the value orientations of the personality as the most important structural formation of the personality and expresses the individual's selective attitude to the basic social values (Alekseeva V, 1984).

V. Kharchev takes a similar position, believing that value orientations are one of the most important elements of the personality structure since they express in a concentrated form subjective attitudes towards the objective conditions of his being, a certain direction of her behavior (Abulkhanova K, 2001).

V. Vodzinsky understands by the value orientations of the personality, a certain structure of the personality's relations to the facts of reality, a specific manifestation of relations, proceeds in the form of fixed attitudes.

V. Sagatovskiy understands by value orientations the system of personal values and the focus of consciousness on their implementation.

According to the philosopher, M. Mamardashvili, as the highest value, calls a person; it is the starting point in the scale of universal values. MM Bakhtin expressed this point of view in his time. Solving the problem of orientation and choice, MM Bakhtin connected it with human culture; he defined it as a "responsible human being, offers free choice of action and personal responsibility for it (Asmolov A, 2007).

An interesting point of view of $\mathrm{V}$. Didenko, which refers to the highest values of life in its individual, tribal and planetary-cosmic dimensions, creativity, as an active human way of life, will, as a deep, necessary condition and the ultimate goal of human life and society.

Value orientations, being one of the central personality new formations, express a person's conscious attitude to social reality and, in this capacity, determine the broad motivation of his behavior and influence all aspects of his reality. Of particular importance is the connection between value orientations and the orientation of the personality. The system of value orientations determines the content side of the individual's orientation and forms the basis of her views on the world around her, towards other 
people, towards herself, the basis of the worldview, the core of motivation, and the "philosophy of life."

The orientation of the personality expresses one of its most essential characteristics, which determines the social and moral value of the individual. First of all, the content of orientation is the dominant, socially conditioned relationship of the individual to the surrounding reality. Through the orientation of the personality, its value orientations find their real expression in the active activity of a person; that is, they must become stable motives of activity and turn into beliefs.

Value orientations are formed based on higher social needs, and their realization takes place in general social, social-class conditions of activity. They are constituent elements of consciousness, part of its structure. In this regard, they obey the principle of the unity of consciousness and consciousness and activity (Anokhin P, 1975).

That is why we say that value orientations are a reflection in the consciousness of a person of values recognized by him as strategic life goals and general worldview guidelines (Abulkhanova-Slavskaya $\mathrm{K}$, 1991).

In modern science, the concept of "value orientations" is correlated with the value standards of a group, class, nation, social system, on the one hand, and, on the other, with the motivational orientations of the individual.

General human values, freedom, conscience, happiness characterize the final ideas of a person about a decent life. The personal hierarchy of values is irreproducible and strictly individual. The combination of relationships and interconnections of value choices is endless. Tracking an individual's social development is carried out through the dynamics of his specific and private relationships to universal values that accumulate the achievements of culture.

The formation of value orientations is a complex and lengthy process that involves scientific knowledge of the psychological mechanisms underlying value orientations and the conditions for their development.

Each personality has its own system of value orientations, in which values are built in a certain hierarchical relationship. Of course, these systems are individual.
In the process of identifying the value orientations of citizens, as an indicator of a certain level of development of their personality, it is necessary to take into account two main parameters: the degree of formation of the hierarchical structure of value orientations and the content of value orientations (their orientation), characterized by specific values included in the structure.

The first parameter is very important for assessing the level of personal maturity. The fact is that the interiorization of values as a conscious process occurs if there is an ability to single out from a set of phenomena those that are of some value to a person (satisfy his needs and interests), and then turn them into a certain structure depending on the conditions, close and distant goals of his whole life, the possibility of their realization and the like. It is easy to see that this ability can be realized only with a high level of personal development, including a certain degree of formation of the higher mental functions of consciousness and socio-psychological maturity

The second parameter, which characterizes the peculiarities of the functioning of value orientations, makes it possible to qualify the content side of the orientation of a person who is at a particular level of development. Depending on what specific values are included in the structure of the individual's value orientations, the combination of these values and the degree of their greater or lesser preference over others, etc., it is possible to determine what life goals a person's activity is directed towards. Analysis of the content side of the hierarchical structure of value orientations can also show the extent to which the value orientations of students are revealed correspond to the social standard, to what extent they are adequate to the goal of education (Bekh I, 1996).

The world of human values is incredibly diverse, so they can be classified on many grounds. The criterion can be the objective characteristics of phenomena that act as values (on this basis, values are divided into material and spiritual). Differentiating by subjects and carriers, society's values as a whole, social group (for example, youth), collective, individual are distinguished. According to the spheres of life, it can be grouped into moral values, economic, political, religious, civil, and others (Anisimov S, 1970).

From a formal point of view, values are divided into positive and negative (among them, low value can be distinguished), absolute and relative, subjective and 
objective. According to the content, material values are distinguished, logical, and aesthetic (Ananiev B, 2001).

Attention should be paid to those values that sociologists and psychologists call basic. They constitute the core of the individual's value consciousness, causing her actions in various spheres of life. If we correlate them with the needs, as many researchers have done and continue to do, then the number of values can be quite small. As you know, Freud reduced them to two, and A. Maslow - to five needs-values. Murray compiled a list of 28 values. M. Rokich counted 18 terminal and about a hundred instrumental values. Thus, there are not so many basic values of an individual (or social group). Nevertheless, their typology is a necessary element of scientific analysis (Astashova N, 2002).

One of the most widespread and generalizing typologies is the division into values-goals and valuesmeans. The foundation of this typology is laid by the ethical concept of the German scientist M. Scheler.

In his typology of values, M. Scheler proceeds from the fact that all human values can be represented in the form of two orders, one on top of the other. One of them builds a value hierarchy according to the criterion of morality, has an objective character. In ascending order, this order is presented as follows: the value of sensations; living room of value; spiritual and religious values (Akhmerov R, 2005). Another order reflects the relationship between the height of a value and its essential carrier. Here the scientist identifies eight groups of values. Their hierarchy (from higher to lower) is as follows:

- Personal and object values;

- Own and other people's values that have the same status;

- Values of acts, functions, reactions;

- Values of persuasion, action, success;

- Values of intention and value of state;

- Values of foundations, forms, relationships;

- Individual and collective values;

- Independent and derivatives (Becker G, 1961).

Within the framework of the actual sociopsychological analysis of values, their division into values-goals and values-means was made by $M$. Rokich. The theoretical premises on which he based his empirical analysis were as follows:

1) The total number of values that are really important and therefore motivate human behavior is small;

2) Similar values, the carriers of which are people who have different significance for each of them;

3) All values are organized into systems;

4) We find the roots of the values of a particular person in the culture of certain social communities, social institutions, in the structure of a person's consciousness;

5) Values influence the functioning of a number of social phenomena that are in the focus of attention of various social sciences and humanities.

Based on this, scientist divides human values into the terminal (for him these are the main guidelines for the behavior of an individual, his goals and ideals) and instrumental (means of achieving goals and realizing ideals). M. Rokich, in turn, divides terminal values into personal and social, and instrumental ones into moral and competence values (Ananiev B, 2001).

Nevertheless, it should be considered that the division of values into two main types is very relative, like any other typology. In this case, relativity is determined by the close functional relationship that exists between the terminal and instrumental values. First of all, this dependence manifests itself in the possibility of their mutual substitution. That is, in a certain situation, the terminal value can become instrumental and vice versa. This depends not only on its carriers (for whom the value, for example, of education, maybe terminal, for someone - only instrumental) (lasechko, M., Tymochko O., Shapran Y., Trofymenko I., Maksiuta D., and Sytnyk Y, 2019).

Many researchers of the twentieth century based their typology of values, proceeding from human needs, considering them as the deepest formations in the structure of human consciousness. So, E. Fromm classifies values following five groups of needs identified by him:

- The need for communication (interpersonal relationships, love, friendship); 
- $\quad$ The need for creativity;

- $\quad$ Need for security;

- $\quad$ Need for self-identification;

- $\quad$ The need for knowledge of the surrounding world (Becker G, 1961).

This classification of the individual's basic needs turned out to be very productive, as well as the typology of needs presented by the famous American psychologist A. Maslow. In fact, identifying needs and values, A. Maslow, in his hierarchical typology of needs: from physiological needs (for food, clothing, housing, reproductive needs, etc.), which he calls the primary elements in motivating a person's behavior, comes down to needs:

- Existential (need for safety, confidence in the future, stability of living conditions, etc.);

- Social (the need for communication, caring for other people, attachment to a particular team)

- Needs of prestige (the need for respect, recognition, high appreciation from other people in a professional career, increasing social status);

- Needs of self-expression, the realization of spiritual needs, first of all, is actualized in creativity (Ananiev B, 2001).

At the same time, A. Maslow believes that the activation of higher rank needs occurs only if the needs at the base of the presented hierarchy are satisfied.

Another approach to the consideration of values is presented in the works of E. Vishnevsky. In his value hierarchy, a special place is occupied by such universal, eternal values as kindness, truth, love, honesty, dignity, beauty, wisdom, justice, etc.

The works of $\mathrm{E}$. Vishnevsky belong to the few publications dealing with the problem of civic values. At the same time, the author emphasizes that the latter are based on the recognition of equality between people and manifest themselves mainly in the conditions of the dominance of the principles of democracy, in the conditions of civil society. Note that in civic values, $\mathrm{E}$. Vishnevsky includes such as recognition of human rights and freedoms, respect for the law, the idea of social harmony, etc. Harmony of functioning and balance of relations between various value system elements is achieved by the primacy of universal values (Ananiev B, 2001).

V. Yadov, N. Lapin, N. Naumova, I. Popov divides the system of values and value orientations into generally accepted, dominant, and value periphery. They believe that dominant values, which are sometimes called "structural reserve" due to their ability to move both to the "core" and the "periphery" of the value structure, have significant dynamism. However, the most transformative potential is possessed by opposition values, which can move (especially during periods of cardinal socio-cultural changes) not only at the level of dominant but even "nuclear" values. (lasechko, M., Gnusov, Y., Manzhai I., Uhrovetskyi O., Manoylo V., lesipov A.., Zaitsev O., Volk M., and Vovk O. 2019).

Summing up all that has been said above, we can conclude that there are a large number of concepts and theories for determining values and value orientations. But the main thing is that value does not exist by itself but manifests itself as an element of the action of the individual and the social group. Values can be both absolute; they can be in the form of material and nonmaterial objects, or the person himself, in his biological needs.

It should be noted that the new value system of Ukrainian society is just beginning to emerge. This process is contradictory. Value ambivalence, a conflict of values, often provokes social and sociopsychological tension in society. However, it is precisely the inconsistency that provides value phenomena with a dynamic character, which allows their subjects and carriers to adapt more quickly, and the complex conditions of society are changing.

\section{CONCLUSION}

As a result of the theoretical analysis, it was clarified, firstly: value orientations - a complex sociopsychological phenomenon that characterizes the orientation and content of a person's activity, determine the general approach of a person to the world, to himself, giving meaning and direction to personal positions, behavior, and actions.

Secondly, the system of personal value orientations has a multilevel structure, the peak of which is the values associated with the idealization and life goals of a person. 


\section{REFERENCES}

Abulkhanova K. (2001). Personality time and life time. - pp. 304.

Abulkhanova-Slavskaya K. (1991). Life strategy. - pp. 229.

Akhmerov R. (2005). Psychobiographical characteristics of a subject with an autonomous type of self-regulation of activity. - pp. 25-34.

Alekseeva V. (1984). Value orientations as a factor of life and personality development. - pp. 63-70.

Ananiev B. (2001). Man as a subject of knowledge. - pp. 288.

Ananiev B. (2001). Man as a subject of knowledge. - pp. 288.

Andreeva G. (2004). Psychology of social cognition. - pp. 288.

Anisimov S. (1970). Real and imaginary values. - pp. 183.

Anokhin P. (1975). Essays on the physiology of functional systems. pp. 448 .

Asmolov A. (2007). Personality psychology: cultural and historical understanding of human development. - pp. 528.

Astashova N. (2002). Conceptual foundations of pedagogical axiology. - pp. 8-13.

Babasov E. (2001). Dynamics of value orientations of young people in a transforming society. - pp. 159.

Badmaev B. (2001). Teaching methodology psychologists. - pp. 304.

Becker G. (1961). Modern sociological theory in its continuity and change. - pp. 895.

Bekh I. (1996). The problem of personal values: state and research guidelines. - pp. 57-67.

Bulakh IS (2011). Psychological features of school anxiety of junior schoolchildren / International scientific forum: sociology, psychology, pedagogy, management. - V. 7. - pp. 150-157.
Butkivska T.V. (2001). Value dimension of students' socialization / Pedagogy and psychology. - №1. - pp. 130-136.

Golovakha E. I., Kronik A. A. (1984). Personality psychological time. - Kiev: Naukova Dumka. - pp. 208.

lasechko M., Gnusov Y., Manzhai I., Uhrovetskyi O., Manoylo V., lesipov A.., Zaitsev O., Volk M., and Vovk O. (2019). Determination of requirements for the protection of radioelectronicequipment from the terroristic influence by electromagnetic radiation, . - IJETER. - 7(12) . - pp. 772 777.

https://doi.org/10.30534/ijeter/2019/077122019

lasechko, M. , Tymochko O., Shapran Y., Trofymenko I., Maksiuta D., and Sytnyk Y. (2019). Loss definition of charged particles in the discharge gap of the opening of the box-screens during the formation of a highly conductive channel. JATCSE. 8(1.3) . - pp. 1-9.

https://doi.org/10.30534/ijatcse/2019/0181.32019

Leontiev A. A. (1997). Psychology of communication. - 2nd ed. - M.: Meaning. (Ser. "Psychology for the student", issue 4). - pp. $365 \mathrm{p}$.

Petrovsky A.V. (2002). Psychology. - M .: Academy, - pp. 512.

Sadova T. (2010). Axiological approach in the pedagogical system methodology / Preschool education. - № 1 (27). - pp. 63-69.

Uznadze D.N. (2004). General psychology. SPb .: 2004 - pp. 413.

Voitko V.I. (1982). Psychological dictionary. - Kyiv: Higher school [2]. - pp. 214.

Vyshnevsky O. (2005). Pedagogy in search of spirituality / Native school. - № 7. - pp. 3-5.

Yadov V.A. (1994). Social identification in a crisis society / Sociological journal. - № 1. - pp. 35-52.

Received on 16-02-2021

Accepted on 29-03-2021

Published on 06-04-2021

https://doi.org/10.6000/1929-4409.2021.10.89

(C) 2021 Liakisheva et al.; Licensee Lifescience Global.

This is an open access article licensed under the terms of the Creative Commons Attribution Non-Commercial License (http://creativecommons.org/licenses/by-nc/3.0/) which permits unrestricted, non-commercial use, distribution and reproduction in any medium, provided the work is properly cited. 